\title{
A novel mutation of the calcium-sensing receptor gene in a Greek family from Nisyros
}

\author{
Evaggelia Zapanti, ${ }^{1}$ Aikaterini Polonifi, ${ }^{2}$ Michalis Kokkinos, ${ }^{2}$ George Boutzios, ${ }^{2}$ \\ Georgia Kassi, ${ }^{1}$ Narjes Nasiri Ansari, ${ }^{3}$ Eva Kassi, ${ }^{3}$ Aris Polyzos ${ }^{2}$
}

${ }^{1}$ First Endocrine Department, Alexandra Hospital, Athens, ${ }^{2}$ First Department of Internal Medicine, Laikon General Hospital, Athens University School of Medicine, Athens, ${ }^{3}$ Department of Biological Chemistry, Medical School, University of Athens, Athens, Greece

\begin{abstract}
PURPOSE: Inactivating mutations of the calcium-sensing receptor (CASR) gene cause familial hypocalciuric hypercalcaemia (FHH). Here we report three siblings with FHH caused by a novel mutation in the CASR. METHODS: The case subject was a 60 -year-old patient referred because of mild hypercalcaemia, increased PTH levels and persistently low calcium/creatinine ratio. FHH was suspected and a family biochemical and genetic analysis was performed. RESULTS: Sequencing of the CASR gene revealed a frameshift mutation (Val258Arg) in the extracellular domain of the $C A S R$ that creates a premature 46 amino acids stop codon which leads to a truncated protein that might affect its function. This heterozygous loss-of-function mutation in the CaSR gene causes reduced CaSR sensing ability resulting in the clinical manifestation of FHH. CONCLUSION: We hereby report the identification of a novel heterozygous loss-offunction mutation of the CASR gene in a Greek family from Nisyros island. Functional studies are needed to clarify the exact role of this mutation in CASR activity.
\end{abstract}

Key words: Calcium-sensing receptor, Familial hypocalciuric hypercalcaemia, Mutation, Single nucleotide polymorphism

\section{INTRODUCTION}

The calcium-sensing receptor (CASR) is a $\mathrm{G}$ protein-coupled receptor that is mainly expressed in the parathyroids and the kidneys where it regulates

Address for correspondence:

Eva N. Kassi, Assistant Professor, Laboratory of Biological Chemistry, Medical School, University of Athens,

75 Mikras Asias Str., P.C. 11521, Goudi, Athens, Greece,

Tel. +30 210-6513529, Fax: +30 210-7462703

E-mail: ekassi@med.uoa.gr

Received: 20-10-2014, Accepted: 21-10-2014 parathyroid hormone secretion and renal tubular calcium reabsorption.

Inactivating and activating $C A S R$ gene mutations cause hypercalcaemic or hypocalcaemic disorders, respectively. Inactivating mutations of the receptor result in familial hypocalciuric hypercalcaemia (FHH) (heterozygous for loss-of-function mutations) and neonatal severe hyperparathyroidism (NSHPT) (homozygous for loss-of-function mutations), whereas activating CASR mutations (heterozygous gain-offunction CASR mutations) result in familial/sporadic 
autosomal dominant hypocalcaemia with hypercalciuria (ADHH). ${ }^{1}$ Familial hypocalciuric hypercalcaemia is a rare benign condition inherited as an autosomal dominant trait caused by inactivating mutations of the $C A S R$ gene. FHH is characterized by a modest elevation of the serum calcium (serum calcium within $10 \%$ of the upper limit of normal), moderate hypophosphataemia, relative hypocalciuria (urinary calcium/creatinine clearance ratio $<0.01$ ) and nonsuppressed PTH levels. ${ }^{2,3}$ FFH patients are mostly asymptomatic and the disorder is often diagnosed during a routine blood test. We report a novel mutation of the CASR gene in three siblings with $\mathrm{FHH}$ from a Greek island (Nisyros).

\section{MATERIALS AND METHODS}

\section{Patients}

The first patient, a 60-year old women, was referred because of a mild case of hypercalcaemia. Biochemical tests showed an elevation of her serum $\mathrm{Ca}$ and PTH levels and decreased urine calcium levels (Table 1). Family screening revealed that the two other siblings, a 50-year old sister and a 68-year old brother, had the same biochemical features. FHH was suspected and a genetic analysis was performed.

\section{DNA extraction}

Venous blood samples were collected from the proband and her family members. Blood DNA was extracted from $3 \mathrm{ml}$ peripheral blood using the QIAamp Blood Kit (Qiagen, Hilden, Germany). The study was developed in agreement with the policy statement of the Declaration of Helsinki and performed with the approval of the Committee on Biomedical Ethics of the University of Athens (Greece). Written informed consent was obtained from all subjects.

\section{Sequencing analysis of the CaSR gene}

DNA sequence of the CaSR gene of the proband was analyzed by PCR amplification of all coding exons and intron-exon junctions for the CaSR gene (Gen Bank Accession number NM:000388.3) and direct sequencing of PCR products. The identified mutation was also evaluated in the patient's family members by PCR-based sequencing. Exon 4 was amplified by two PCR reactions which produce two overlapping PCR products. The primers used were forward: 5'-GGTCAGTTATGCC TCCTCCA-3' and reverse: 5'-CCTTCAGAGCGAATCCAATG-3' for the first amplicon of 479bp and forward: 5 '-GCCATGCCTCAGTACTTCCA-3' and reverse: 5'-CGCCTCAACTTTCTTGATGTC-3' for the second amplicon of $456 \mathrm{bp}$. For exon 7 a PCR reaction of $316 \mathrm{bp}$ amplicon was generated with forward and reversed primers, 5'-GAGTTGTCCCCAGCACTTGT-3' and 5'-GCAACCACAGAAACAC-AAGG-3' respectively, while for intron 3 a 275bp PCR amplicon was generated with, forward: 5'-CCCTCTACGATTGCTGTGGT-3' and reverse: 5'-TCATTGATATTGTGGACACTGGA-3'. The PCR conditions were 1 cycle of $2 \mathrm{~min}$ at $94^{\circ} \mathrm{C}$, and 30 cycles of $30 \mathrm{~s}$ at $94^{\circ} \mathrm{C}, 30 \mathrm{~s}$ at $60^{\circ} \mathrm{C}$ and $90 \mathrm{~s}$ at $72^{\circ} \mathrm{C}$ for followed by 1 cycle at $72^{\circ} \mathrm{C}$ for 7 minutes. PCR products were electrophoresed through $3 \%$ agarose gels and were directly sequenced and read in both directions using the BigDye ${ }^{\circledR}$ Terminator v3.1 ready reaction sequencing kit and $\mathrm{ABI}$ model $3730 \mathrm{xl}$ DNAAnalyzer (Applied Biosystems, USA) according to the manufacturer's instructions.

\section{RESULTS}

Table 1 summarizes the biochemical tests of the three siblings. All three siblings exhibited normal serum magnesium values and 25(OH)vitamin D levels at the lower limit of the normal range (Table 1).

Table 1. Biochemical features of the FHH proband and siblings

\begin{tabular}{|c|c|c|c|c|c|c|c|c|c|c|c|}
\hline $\begin{array}{l}\text { Reference } \\
\text { range }\end{array}$ & $\begin{array}{c}\mathrm{s}-\mathrm{Ca} \\
(8,6-10.2 \\
\mathrm{mg} / \mathrm{dl})\end{array}$ & $\begin{array}{c}\mathrm{s}-\mathrm{P} \\
(2.5-4.5 \\
\mathrm{mg} / \mathrm{dl})\end{array}$ & $\begin{array}{c}\text { s-Alb } \\
(3.5-5.2 \\
\text { g/dl) }\end{array}$ & $\begin{array}{c}\text { s-Crea } \\
(0.6-1.1 \\
\mathrm{md} / \mathrm{dl})\end{array}$ & $\begin{array}{c}\text { s-Mg } \\
(1.6-2.4 \\
\mathrm{mg} / \mathrm{dl})\end{array}$ & $\begin{array}{c}\text { s-PTH } \\
(8-76 \\
\mathrm{pg} / \mathrm{ml})\end{array}$ & $\begin{array}{c}25(\mathrm{OH}) \mathrm{D} \\
(>30 \mathrm{ng} / \mathrm{ml})\end{array}$ & $\begin{array}{c}\text { u-Ca } \\
(100-300 \\
\mathrm{mg} / 24 \mathrm{~h})\end{array}$ & $\begin{array}{c}\text { u-Crea } \\
(0.8-1.8 \\
\text { g/24h) }\end{array}$ & $\begin{array}{c}\text { s-alp } \\
(48-141 \\
\text { U/L) }\end{array}$ & $\begin{array}{c}\mathrm{CaCl} / \\
\text { Crea. Cl. }\end{array}$ \\
\hline$\overline{\mathrm{Z} 1}$ & 10.8 & 3.4 & 3.9 & 0.8 & 2.1 & 70 & 19 & 110 & 1.1 & 69 & 0.007 \\
\hline Z2 & 10.3 & 3.9 & 4.2 & 0.7 & 2.3 & 61 & 15 & 90 & 1.3 & 55 & 0.004 \\
\hline $\mathrm{Z3}$ & 10.6 & 2.8 & 4.4 & 1 & 1.9 & 66 & 18 & 80 & 0.9 & 76 & 0.008 \\
\hline
\end{tabular}

Ca: calcium; P: phosphate; Alb: albumin; crea: creatinine; Mg: magnesium; PTH: parathormone; alp: alkaline phosphate; s: serum; u: urine. 
Table 2 shows the results of sequencing analysis. A novel heterozygous mutation 772_773delGTinsA was identified in exon 4 in the ECD domain in all three siblings. In fact, there was a simultaneous GT deletion and $\mathrm{A}$ insertion which led to a frameshift.

Two known single nucleotide polymorphisms (SNPs) (c.492+19G $>$ A and c. ${ }^{*}+60 \mathrm{~A}>\mathrm{T}$, called from now ownwards polymorphism 1 and polymorphism 2 , respectively) ${ }^{4}$ were also found in homozygous form in the proband and her sister, and in heterozygous form in her brother. Polymorphisms 1 and 2 were detected in intron 3 and in the $3^{\prime}$-untranslated region (UTR) of exon 7, respectively, and were both silent. No correlation between the phenotype of the siblings and specific genotypes was observed.

\section{DISCUSSION}

FHH is a genetic condition causing lifelong hypercalcaemia and relative hypocalciuria owing to inactivation of the CaSR protein in the parathyroids and kidneys. The human CASR gene is located on chromosome 3q13-q21, spans $\sim 103 \mathrm{~kb}$ and has eight exons. ${ }^{1}$ Exons 2-7 encode the CASR protein of 1078 amino acids. Untranslated regions are comprised of exons $1 \mathrm{~A}$ and $1 \mathrm{~B}$, part of exon 2 and part of exon 7. Exons $1 \mathrm{~A}$ and $1 \mathrm{~B}$ encode alternative 5 '-UTRs that splice to the common portion encoded by exon 2 . In exon 7, two different polyadenylation signal sequences (AATAAA) yield either a short (177-nucleotide) or long (1304-nucleotide) 3'-untranslated region (UTR). The CASR glycoprotein belongs to family $\mathrm{C}$ or family 3 of the superfamily of G-protein-coupled receptors and has three structural domains: a large (612 amino acid) extracellular domain (ECD), seven transmembrane domains (TMDs) and an intracellular domain (ICD).

The ECD is critical for co-translational processing, receptor dimerization, binding ligands and transmitting activation signals through the seven TMDs. ${ }^{5}$ CaSR is expressed mainly in the parathyroid glands, kidneys and thyroid $\mathrm{C}$ cells and at lower levels in the pancreas, gut, liver and chondrocytes. ${ }^{3}$ Under normal conditions, CaSR has the central role in maintaining constant circulating calcium levels. CaSR can sense even minute changes in calcium concentrations. ${ }^{6}$ When activated by increased calcium levels it inhibits PTH secretion. In contrast, when CaSR senses decreased calcium levels, it stimulates PTH secretion and the translocation of calcium ions into the extracellular fluid. ${ }^{7}$ Furthermore, activation of the CaSR in the nephron decreases calcium and magnesium reabsorption. ${ }^{7}$ In FHH there is a heterozygous loss-of-function mutation in the CaSR gene that causes reduced CaSR sensing ability. This results in an increase in the set point of the parathyroid glands. ${ }^{8}$ This set point is defined as the level of calcium at which the suppression of PTH is half maximal. The alteration in the set point brought about by FHH means that the parathyroid glands exhibit resistance to circulating calcium, with failure of PTH response, resulting in hypercalcaemia

Table 2. Results of sequencing analysis showing the novel mutation and the known polymorphisms $(1,2)$ in the CaSR of proband and family genetic profile

\begin{tabular}{|c|c|c|c|c|}
\hline Patient & $\begin{array}{c}\text { DNA (Gen Bank Accession } \\
\text { number NM:000388.3 }\end{array}$ & DNA change & Protein change & Result \\
\hline $\mathrm{Z1}$ & Intron3 & c.492+19G >A homozygous & - & Polymorphism1 \\
\hline $\mathrm{Z} 2$ & Intron3 & c. $492+19 \mathrm{G}>$ A homozygous & - & Polymorphism 1 \\
\hline $\mathrm{Z3}$ & Intron3 & c. $492+19 \mathrm{G}>\mathrm{A}$ heterozygous & - & Polymorphism1 \\
\hline $\mathrm{Z1}$ & Exon 4 & c. $772 \_773$ delGTinsA heterozygous & pVal258ArgfsX47 & Mutation \\
\hline $\mathrm{Z} 2$ & Exon 4 & c. $772 \_773$ delGTinsA heterozygous & pVal258ArgfsX47 & Mutation \\
\hline $\mathrm{Z3}$ & Exon 4 & c. $772 \_773$ delGTinsA heterozygous & pVal258ArgfsX47 & Mutation \\
\hline $\mathrm{Z1}$ & Ex7-3'UTR & c. $* 60 \mathrm{~A}>\mathrm{T}$ homozygous & - & Polymorphism2 \\
\hline $\mathrm{Z} 2$ & Ex7-3'UTR & c. $* 60 \mathrm{~A}>\mathrm{T}$ homozygous & & Polymorphism2 \\
\hline $\mathrm{Z3}$ & Ex7-3'UTR & c. $* 60 \mathrm{~A}>\mathrm{T}$ heterozygous & & Polymorphism2 \\
\hline
\end{tabular}

Z1: ZS, proband; Z2: ZP, sister; Z3: ZB, brother; Polymorphism1: rs9869985; Polymorphism2: rs 4677948. 
and inappropriately high PTH levels. ${ }^{9}$ In addition, inactivation of CASR in the kidneys induces an intrinsic tubular abnormality that leads to diminished urinary calcium secretion. In FHH patients there is a high tubular reabsorption of calcium and magnesium. FHH is generally benign and asymptomatic. Occasionally some patients may manifest weakness, fatigue and polydipsia. ${ }^{9}$ The incidence of complications associated with PHPT, such as osteoporosis and nephrolithiasis, is not increased in FHH patients. The intestinal absorption of calcium and the levels of circulating vitamin $\mathrm{D}$ are usually normal. ${ }^{3}$ A positive family history and a calcium:creatinine clearance ratio $(\mathrm{CCCR})<0.01$ may suggest the diagnosis of FHH. However, the most helpful method for the confirmation of the diagnosis (even though not $100 \%$ sensitive) is genetic testing for mutations of the CASR. ${ }^{10}$

To date, more than 200 naturally occurring mutations have been reported (see online database at http://www.casrdb.mcgill.ca) that include missense, nonsense, deletion, insertion and splice mutations. ${ }^{11}$ The majority of them are loss-of-function mutations. Patients with two affected gene copies present with neonatal and often fatal hyperparathyroidism manifested by severe hypercalcaemia.

Herein we present three siblings with a novel inactivating heterozygous mutation in the extracellular aminoterminal domain in exon 4 of the CaSR gene.

The existence of this novel mutation is substantiated by the fact that the observed deletion of GT and insertion of A is not present in 100 chromosomes of normal volunteers. Moreover, it leads to a substitution of Valine at amino acid position 258 (a neutral non polar-hydrophobic amino acid) for Arginine which is a positively charged polar-hydrophilic amino acid. This, in turn, results in a change in molar mass of the amino acid from $117.15 \mathrm{~g} \mathrm{~mol}^{-1}$ to $174.20 \mathrm{~g}$ $\mathrm{mol}^{-1}$, thus the space occupied in the protein chain is significantly bigger. It should be noted that Valine is well-conserved in homology and in the closest genes of C. elegans and A. thaliana. Finally, and more importantly, this mutation, occurring in the middle of the cDNA sequence, causes a frameshift that creates a premature 46 amino acids stop codon which leads to a truncated protein that might affect its function. Although the initial prediction pointed to the frameshift mutation probably being gene-damaging, the phenotype of the proband -as well as of the other two siblings- was mild. This could be attributed to a low mutant: wild type allelic ratios at the genomic level. However, the co-existence of somatic mutation (occurring in the target organs such as parathyroids and kidneys) that could restore the disturbed order of the frame cannot be excluded.

The three siblings also carried two known silent polymorphisms. Polymorphism 1 is within intron 3 but close enough to the intron-exon boundary to be detected during standard mutation analysis of the CASR.

Polymorphism 2 was found by Yun et al to be relatively rare in both Asians and Caucasians ( $\mathrm{MAF}=0.045$ and 0.023 , respectively), while it had a statistically higher frequency (MAF=0.202) in African-Americans. ${ }^{4}$ It should be noted that the only intron mutation found to be functional (using in vitro assay) is a splice variant at the IVS2/exon 3 boundary. ${ }^{12}$ The role of SNPs in the pathogenesis of disorders of bone and mineral metabolism is the subject of ongoing investigation and there is evidence that the two SNPs may be associated with a more diverse set of phenotypes reflecting widespread expression of the CASR.

In conclusion, we report the identification of a novel heterozygous loss-of-function mutation of the $C A S R$ in a Greek family from Nisyros island. Functional studies are needed to clarify the exact role of this mutation on CASR activity.

\section{DECLARATION OF INTEREST}

There is no conflict of interest.

\section{REFERENCES}

1. Thakker V, 2004 Diseases associated with the extracellular calcium-sensing receptor. Cell Calcium 35: 275-282.

2. Bilezikian P, Potts T, Fuleihan H, et al, 2002 Summary statement from a workshop on asymptomatic primary hyperparathyroidism: a perspective for the $21^{\text {st }}$ century. J Clin Endocrinol Metab 87: 5353-5361.

3. Hendy N, Guarnieri V, Canaff L, 2009 Calcium-sensing receptor and associated diseases. Prog Mol Biol Transl Sci 89: 31-95.

4. Yun H, Wong Y, Chase M, et al, 2007 Genetic variation at the calcium-sensing receptor (CASR) locus: 
implications for clinical molecular diagnostics. Clin Biochem 40: 551-561.

5. D'Souza-Li L, Yang B, Canaff L, et al, 2002 Identification and functional characterization of novel calciumsensing receptor mutations in familial hypocalciuric hypercalcaemia and autosomal dominant hypocalcaemia. J Clin Endocrinol Metab 87: 1309-1318.

6. Brown M, 2000 Familial hypocalciuric hypercalcemia and other disorders with resistance to extracellular calcium. Endocrinol Metab Clin North Am 29: 503-522.

7. Khosla S, EbelingR, FirekF, Burritt M, Kao C, Heath H, 1993 Calcium infusion suggests a "set-point" abnormality of parathyroid gland function in familial benign hypercalcemia and more complex disturbances in primary hyperparathyroidism. J Clin Endocrinol Metab76: 715-720.

8. Varghese J, Rich T, Jimenez C, 2011 Benign Familial
Hypocalciuric Hypercalcemia. Endocr Pract 17: 13-17. 9. Shinall C, McCrystal Dahir K, Broome T, 2014 Differentiating Familial Hypocalciuric Hypercalcemia from Primary Hyperparathyroidism. Endocr Pract19: 697-702.

10. Pidasheva S, D’Souza-Li L, Canaff L, Cole E, Hendy N, 2004 CASRdb:calcium-sensing receptor locus-specific database for mutations causing familial (benign) hypocalciuric hypercalcemia. Hum Mutat 24: 107-111.

11. Kristiansen H, Rødbro P, Christiansen C, Brøchner J, Carl J, 1985 Familial hypocalciuric hypercalsaemia II in testinal calcium absorption and vitamin D metabolism. Clin Endocrinol 23: 511-517.

12. D’Souza-Li L, Canaff L, Janicic N, Cole E, Hendy N, 2001 An acceptor splice site mutation in the calciumsensing receptor $(C A S R)$ gene in familial hypocalciuric hypercalcaemia and neonatal severe hyperparathyroidism. Hum Mutat 18: 411-421. 